\title{
Transcatheter aortic valve implantation versus surgical aortic valve replacement: A propensity score analysis in patients at high surgical risk
}

\author{
Lenard Conradi, MD, ${ }^{\mathrm{a}}$ Moritz Seiffert, MD, ${ }^{\mathrm{a}}$ Hendrik Treede, MD, ${ }^{\mathrm{a}}$ Miriam Silaschi, ${ }^{\mathrm{a}}$ \\ Stephan Baldus, MD, ${ }^{\mathrm{b}}$ Johannes Schirmer, MD, ${ }^{\mathrm{a}}$ Jan-Felix Kersten, ${ }^{\mathrm{c}}$ Thomas Meinertz, MD, ${ }^{\mathrm{b}}$ and \\ Hermann Reichenspurner, $\mathrm{MD}, \mathrm{PhD}^{\mathrm{a}}$
}

\begin{abstract}
Objectives: Transcatheter aortic valve implantation (TAVI) has recently been advocated to decrease perioperative risk in high-risk patients. In this propensity-score analysis we compared outcomes after TAVI to those after surgical aortic valve replacement (AVR).
\end{abstract}

\begin{abstract}
Methods: From June 2009 through June 2010, 82 consecutive patients underwent TAVI via a transapical $(\mathrm{n}=60)$ or transfemoral $(\mathrm{n}=22)$ approach using the Edwards Sapien prosthesis (Edwards Lifesciences, Irvine, Calif). Mean patient age was $81.9 \pm 5.2$ years, $64.6 \%$ were women. Logistic EuroSCORE was $23.6 \% \pm 1.4 \%$ and Society of Thoracic Surgeons score was $8.7 \% \pm 1.3 \%$. A group of 82 patients after surgical AVR was retrieved from our database, yielding a control group that was matched to the cases with respect to baseline demographics and typical risk factors.
\end{abstract}

\begin{abstract}
Results: Overall mortality did not differ significantly between TAVI and AVR groups at 30 days $(7.3 \%$ vs $8.6 \%)$, 90 days $(13.6 \%$ vs $11.1 \%)$, or 180 days $(17.8 \%$ vs $16.9 \% ; P=.889)$. Conversion to surgery was necessary in $2(2.4 \%)$ TAVI cases. Perioperative stroke occurred in $2(2.4 \%)$ cases per group. Pacemakers were implanted for new-onset heart block in $3.7 \%$ and $2.4 \%$ in the TAVI and AVR groups, respectively $(P=1.0)$. TAVI resulted in shorter operative times $(P<.001)$, shorter ventilation times $(P<.001)$, and shorter length of stay in the intensive care unit $(P=.008)$. Duration of hospital stay, however, was not significantly different $(P=.11)$.
\end{abstract}

Conclusions: In our experience, mortality rates are similar after both types of procedure. Patients receiving TAVI benefit from faster postoperative recovery. Until more clinical data become available, the optimal procedure has to be determined for each patient according to individual risk factors. (J Thorac Cardiovasc Surg 2012;143:64-71)

Calcific aortic stenosis is a progressive and irreversible condition with a dismal prognosis if left untreated. Until recently, surgical substitution of the native valve by a biological or mechanical heart valve prosthesis was the only durable treatment option. Surgical aortic valve replacement (AVR) can be performed in a highly standardized manner with low perioperative morbidity and mortality even in octogenarians. ${ }^{1-4}$ or patients deemed at high surgical risk $^{5}$ and has to serve as the clinical benchmark for any new treatment option. It provides lasting relief of

From the Department of Cardiovascular Surgery, ${ }^{\mathrm{a}}$ University Heart Center Hamburg; and the Departments of Cardiology ${ }^{\mathrm{b}}$ and Medical Biometry and Epidemiology, University Medical Center Hamburg-Eppendorf, Hamburg, Germany.

Disclosures: Authors have nothing to disclose with regard to commercial support. L.C. and M.S. contributed equally to this work.

Read at the 91st Annual Meeting of The American Association for Thoracic Surgery, Philadelphia, Pennsylvania, May 7-11, 2011.

Received for publication April 30, 2011; revisions received July 21, 2011; accepted for publication Aug 24, 2011; available ahead of print Nov 4, 2011.

Address for reprints: Lenard Conradi, MD, University Heart Center Hamburg, Department of Cardiovascular Surgery, University Medical Center Hamburg-Eppendorf, Martinistrasse 52, D-20246 Hamburg, Germany (E-mail: lconradi@uke.de).

$0022-5223 / \$ 36.00$

Copyright (C) 2012 by The American Association for Thoracic Surgery doi:10.1016/j.jtcvs.2011.08.047 symptoms and results in improved quality of life and excellent short- and long-term survival. Owing to the low perioperative morbidity, AVR may be indicated even in asymptomatic patients with severe aortic stenosis. ${ }^{6}$ However, it is a clinical reality that a substantial share of patients are denied surgery as a result of presumed or real contraindications or because operative risk is deemed prohibitively high owing to comorbidities. ${ }^{7}$ It is for this growing population of high-risk patients that less invasive, beating-heart transarterial retrograde or transapical antegrade aortic valve implantation (TAVI) procedures have been developed and introduced into clinical practice for primary valve implantation, ${ }^{8,9}$ in combination with percutaneous coronary interventions ${ }^{10}$ or even for redo valve-in-valve procedures. ${ }^{11}$ In this study, outcomes of a cohort of 82 consecutive TAVI procedures were analyzed and compared with a propensity-adjusted control group of patients after surgical AVR.

\section{PATIENTS AND METHODS}

From June 2009 through June 2010, 82 consecutive patients with severe aortic stenosis underwent TAVI via a transapical $(n=60)$ or transfemoral approach $(\mathrm{n}=22)$ using the Edwards Sapien balloon expandable 


\section{Abbreviations and Acronyms \\ AVR = aortic valve replacement \\ LVEF = left ventricular ejection fraction \\ NYHA $=$ New York Heart Association \\ PARTNER $=$ Placement of AoRTic \\ TraNscathetER Valve (trial) \\ PPM = patient-prosthesis mismatch \\ TAVI $=$ transapical antegrade aortic valve implantation}

pericardial xenograft (Edwards Lifesciences, Irvine, Calif). Decisionmaking for TAVI or AVR was a formal process involving a dedicated interdisciplinary heart team of cardiac surgeons, interventional and noninterventional cardiologists, cardiac anesthetists, and intensive care physicians. All patients with elevated risk were discussed in an interdisciplinary conference and were allocated to one or the other treatment option only by mutual agreement. All TAVI procedures were performed by the heart team in a hybrid operating theater. Transesophageal echocardiography and fluoroscopy were used to guide the implantation procedure. TAVI was performed in a standard manner as described previously. ${ }^{12} \mathrm{~Pa}-$ tients considered eligible for TAVI were generally older than 75 years of age although age alone did not qualify as a single criterion for TAVI. All patients were considered to be at high surgical risk owing to comorbidities with a logistic EuroSCORE of $20 \%$ or greater.

Patients deemed poor surgical candidates, were primarily evaluated for a transfemoral approach and allocated to a transapical procedure in case of severe aortoiliac disease or peripheral vessels otherwise unsuitable for transfemoral access. Special consideration was given to sclerosis of the aortic arch, which when present led to a liberal indication of transapical procedures to avoid potential mobilization and embolism of atheroma. Owing to their age and cardiovascular risk profile, sclerosis of the aortic arch is common in the typical TAVI population, leading to a transapical/transfemoral ratio of 2:1 in our overall experience. To derive a surgical control group, we identified 499 patients aged 75 years or older from the hospital records out of a total of 1656 patients treated by isolated AVR for aortic stenosis between 2001 and 2009 at our center. From these, 82 patients were extracted by means of propensity scoring regarding the following variables: age, gender distribution, logistic EuroSCORE, Society of Thoracic Surgeons Predicted Risk of Mortality, New York Heart Association (NYHA) functional class, left ventricular ejection fraction (LVEF), moderate reduction of LVEF (30\%-50\%), severe reduction of LVEF (<30\%), prior stroke, cerebrovascular disease, peripheral artery disease, coronary artery disease, creatinine, diabetes, arterial hypertension, pulmonary hypertension greater than $60 \mathrm{~mm} \mathrm{Hg}$, chronic obstructive pulmonary disease greater than or equal to Global Initiative for Chronic Obstructive Lung Disease II, malignant disease, previous cardiac surgery, atrial fibrillation, and prior pacemaker implantation. Patients were followed up to 180 days after the procedure. Patient data of the 2 respective cohorts are detailed in Table 1.

\section{Statistical Analysis}

Data are presented as absolute numbers and percentages for categorical variables and mean values and standard deviations for continuous variables. Dichotomous variables were compared using Fisher's exact test and continuous variables by $t$ tests. In case of trends for categorical variables, we used the Cochran-Armitage trend test. Kaplan-Meier analysis and $\log$-rank test were used for time-to event analyses. $P$ values are reported without correction for multiple testing. A logistic regression model was used to generate a surgical control group matched for the variables detailed above. All statistical analysis was performed using SPSS 19.0 or the statistical package R version 2.12.2 (SPSS, Inc, Chicago, Ill).

\section{RESULTS \\ Periprocedural Results to 30 Days}

In the TAVI group, procedural success with deployment of a functional prosthesis was achieved in $79(96.3 \%)$ patients. In $2(2.4 \%)$ patients, conversion to surgery and cardiopulmonary bypass became necessary for dislocation of the prosthesis into the left ventricular outflow tract in 1 patient and apical rupture in another. In the surgical group, valve implantation was successful in all cases. Operative times differed significantly between the 2 groups: TAVI $128.9 \pm 9.0$ minutes versus AVR $200.9 \pm 7.6$ minutes $(P=.04)$. There were no intraoperative deaths in the AVR cohort. Two patients in the TAVI cohort died during the procedure $(2.4 \%), 1$ patient owing to a Stanford type A aortic dissection after transfemoral TAVI and 1 patient owing to apical rupture after a transapical procedure. Additional intraoperative data are summarized in Table 2.

In the TAVI cohort, $59(72.0 \%)$ patients were extubated in the operating room immediately after the procedure. Mean ventilation times $(P<.001)$ and mean duration of stay in the intensive care unit $(P=.008)$ were significantly shorter in the TAVI group. Postoperative bleeding $(P=.07)$ and transfusion requirements $(P<.001)$ were also lower in TAVI patients than in the surgical control group. Pacemaker implantation for new-onset total atrioventricular block became necessary in $3(3.7 \%)$ TAVI patients and in 2 $(2.4 \%)$ patients from the surgical cohort. Two $(2.4 \%)$ strokes occurred in each cohort; in the TAVI cohort, 1 stroke occurred after a transfemoral and 1 after a transapical procedure. Echocardiography at discharge revealed good hemodynamic function of the implanted valves. Transvalvular pressure gradients were comparable between the 2 cohorts, whereas mean grade of paravalvular leakage was higher in the TAVI cohort $(P<.001)$. In the TAVI cohort, $50 \%(n=41)$ of patients had some degree of paravalvular leakage, which was trivial to mild in 40 patients and moderate in 1 patient. In the surgical cohort, no paravalvular leakage was observed in any patient. Postoperative transvalvular aortic regurgitation was present in $25.6 \%$ $(n=21)$ of surgical patients and it was trivial in all of these cases. Severe patient-prosthesis mismatch (PPM, defined as an indexed effective orifice area of 0.65 ) or less, was present in $10(12.2 \%)$ TAVI patients. Two of these patients died during follow-up, 1 patient of cancer 260 days after the procedure and another patient of heart failure 160 days after the procedure. In the AVR cohort, severe PPM was present in $1(1.2 \%)$ patient who died on postoperative day 291 after an acute myocardial infarction.

In the present series, $42(51.2 \%)$ TAVI patients had coronary artery disease. In $13(15.9 \%)$ patients, coronary artery disease was treated by percutaneous coronary 
TABLE 1. Baseline demographics and risk factors for the TAVI and the AVR cohorts in the study population

\begin{tabular}{|c|c|c|c|}
\hline & TAVI & AVR & $P$ value \\
\hline $\mathrm{n}$ & 82 & 82 & \\
\hline Age (y) & $81.9 \pm 5.2$ & $82.5 \pm 4.1$ & .39 \\
\hline Female gender & $52(63.4 \%)$ & $48(58.5 \%)$ & .52 \\
\hline LogEuroSCORE $(\%)$ & $23.9 \pm 11.5$ & $23.6 \pm 10.4$ & .85 \\
\hline STS-PROM (\%) & $8.5 \pm 1.3$ & $9.0 \pm 4.9$ & .74 \\
\hline NYHA functional class & $3.1 \pm 0.6$ & $3.2 \pm 0.6$ & .15 \\
\hline NYHA I & $1(1.2 \%)$ & 0 & 1.0 \\
\hline NYHA II & $7(8.5 \%)$ & $5(6.1 \%)$ & .77 \\
\hline NYHA III & $57(69.5 \%)$ & $46(56.1 \%)$ & .11 \\
\hline NYHA IV & $13(15.9 \%)$ & $19(23.2 \%)$ & .32 \\
\hline $\operatorname{LVEF}(\%)$ & $52.5 \pm 8.4$ & $50.6 \pm 10.7$ & .23 \\
\hline LVEF 30\%-50\% & $18(22.0 \%)$ & $22(26.8 \%)$ & .85 \\
\hline LVEF $<30 \%$ & $3(3.7 \%)$ & $8(9.8 \%)$ & .21 \\
\hline Mean EOA $\left(\mathrm{cm}^{2}\right)$ & $0.7 \pm 0.2$ & $0.6 \pm 0.1$ & .02 \\
\hline Peak/mean gradient $(\mathrm{mm} \mathrm{Hg}$ ) & $39.2 \pm 16.3 / 65.0 \pm 24.9$ & $45.8 \pm 16.7 / 75.3 \pm 25.5$ & $.02 / .01$ \\
\hline Prior stroke or TIA & $16(19.5 \%)$ & $14(17.1 \%)$ & .84 \\
\hline Cerebrovascular disease & $19(23.2 \%)$ & $18(22.0 \%)$ & 1.00 \\
\hline Coronary artery disease & $42(51.2 \%)$ & $35(42.7 \%)$ & .35 \\
\hline Peripheral artery disease $>$ Fontaine II $(\%)$ & $16(19.5 \%)$ & $12(14.6 \%)$ & .53 \\
\hline Porcelain aorta $(\%)$ & $2(2.4 \%)$ & 0 & .50 \\
\hline Creatinine $(\mathrm{mg} / \mathrm{dL})$ & $1.4 \pm 1.2$ & $1.3 \pm 0.5$ & .44 \\
\hline Creatinine $>1.8 \mathrm{mg} / \mathrm{dL}(\%)$ & $10(12.2 \%)$ & $7(8.5 \%)$ & .46 \\
\hline Diabetes $(\%)$ & $28(34.2 \%)$ & $25(30.5 \%)$ & .74 \\
\hline Arterial hypertension $(\%)$ & $68(82.9 \%)$ & $73(89.0 \%)$ & .27 \\
\hline Pulmonary hypertension > $60 \mathrm{~mm} \mathrm{Hg} \mathrm{( \% )}$ & $14(17.0 \%)$ & $20(24.4 \%)$ & .34 \\
\hline COPD $\geq$ GOLD II $(\%)$ & $24(29.3 \%)$ & $27(32.9 \%)$ & .74 \\
\hline Malignant disease $(\%)$ & $7(8.5 \%)$ & $2(2.4 \%)$ & .17 \\
\hline Previous cardiac surgery $(\%)$ & $20(24.4 \%)$ & $11(13.4 \%)$ & .11 \\
\hline Atrial fibrillation (\%) & $25(30.5 \%)$ & $35(42.7 \%)$ & .14 \\
\hline Prior pacemaker implantation $(\%)$ & $6(7.3 \%)$ & $5(6.1 \%)$ & 1.00 \\
\hline
\end{tabular}

$\mathrm{n}(\%)$ listed for categorical variables. TAVI, Transapical antegrade aortic valve implantation; AVR, aortic valve replacement; LogEuroSCORE, logistic European system for cardiac operative risk evaluation; STS-PROM, Society of Thoracic Surgeons Predicted Risk of Mortality; NYHA, New York Heart Association functional class; $L V E F$, left ventricular ejection fraction; EOA, effective orifice area; TIA, transient ischemic attack; COPD, chronic obstructive pulmonary disease; GOLD, Global Initiative for Chronic Obstructive Lung Disease.

intervention either as a staged approach at $11.9 \pm 9.6$ days before TAVI $(\mathrm{n}=10)$ or as a single-stage procedure immediately before TAVI $(\mathrm{n}=3)$. Percutaneous coronary intervention was performed with a mean of $1.7 \pm 1.5$ stents and a total stent length of $23.0 \pm 20.1 \mathrm{~mm}$ using bare metal stents in 6 cases and drug-eluting stents in 7 cases.

Mortality rates at 30 days did not differ significantly between TAVI $(\mathrm{n}=6,7.3 \%)$ and AVR cohorts $(\mathrm{n}=7,8.6 \%$; $P=1.0)$. For greater detail of acute clinical and hemodynamic outcomes, see Table 3.

\section{Follow-up Data}

During further follow-up, overall mortality rates were similar for the 2 patient cohorts. For TAVI and AVR, mortality rates were $13.6 \%$ and $11.1 \%(P=0.8)$ at 90 days and $17.8 \%$ and $16.9 \%(P=1.0)$ at 180 days (Figure 1$)$. Whereas the majority of deaths during the 30-day followup were procedure related $(84.6 \%)$ in both cohorts, late mortality was mostly related to the patients' comorbidities.
From $21(25.6 \%)$ patients in the TAVI cohort with an LVEF of $50 \%$ or less, 4 died during follow-up, resulting in a mortality rate of $19.0 \%$, which is insignificantly higher than the $17.1 \%$ in the overall TAVI cohort $(P=.76)$. Furthermore, from $41(50 \%)$ TAVI patients with any degree of paravalvular leakage, aortic regurgitation was graded as mild in 8 and as moderate in 1 patient. Among 9 patients with mild or moderate paravalvular leakage, $1(11.1 \%)$ death occurred at 5 months after the procedure.

Major adverse cardiac and cerebrovascular event rates were also comparable between the 2 groups. Incidence of major adverse cardiac and cerebrovascular events (death, stroke, myocardial infarction, or reoperation) for TAVI and AVR was $16.1 \%$ and $13.5 \%(P=.83)$ at 90 days and $21.7 \%$ and $19.1 \%(P=.84)$ at 180 days (Figure 2). In both groups there were no myocardial infarctions or reoperations during 180 days of follow-up. Clinically, patients improved markedly during the further postoperative course. Preoperatively, the majority of all patients had been in 
TABLE 2. Intraoperative data

\begin{tabular}{lccc}
\hline & $\begin{array}{c}\text { TAVI } \\
(\mathbf{n}=\mathbf{8 2})\end{array}$ & $\begin{array}{c}\text { AVR } \\
(\mathbf{n}=\mathbf{8 2})\end{array}$ & $\begin{array}{c}\boldsymbol{P} \\
\text { value }\end{array}$ \\
\hline Procedure time (min) & $128.9 \pm 9.0$ & $200.9 \pm 58.1$ & $<.0001$ \\
Cardiopulmonary bypass (min) & $\mathrm{n} / \mathrm{a}$ & $111.0 \pm 36.2$ & - \\
Aortic crossclamp time (min) & $\mathrm{n} / \mathrm{a}$ & $70.8 \pm 23.2$ & - \\
Fluoroscopy time (min) & $9.8 \pm 8.5$ & $\mathrm{n} / \mathrm{a}$ & - \\
Contrast agent (mL) & $198.3 \pm 93.1$ & $\mathrm{n} / \mathrm{a}$ & - \\
Valve size (mm) & $24.3 \pm 1.7$ & $22.2 \pm 1.8$ & $<.0001$ \\
$19 \mathrm{~mm}$ & $\mathrm{n} / \mathrm{a}$ & $7(8.5 \%)$ & - \\
$21 \mathrm{~mm}$ & $\mathrm{n} / \mathrm{a}$ & $33(40.2 \%)$ & - \\
$23 \mathrm{~mm}$ & $49(59.8 \%)$ & $31(37.8 \%)$ & - \\
$25 \mathrm{~mm}$ & $\mathrm{n} / \mathrm{a}$ & $7(8.5 \%)$ & - \\
$26 \mathrm{~mm}$ & $30(36.6 \%)$ & - & - \\
$27 \mathrm{~mm}$ & $\mathrm{n} / \mathrm{a}$ & $4(4.9 \%)$ & - \\
$29 \mathrm{~mm}$ & $3(3.7 \%)$ & - & - \\
Procedural success $(\%)$ & $79(96.3 \%)$ & $82(100.0 \%)$ & .25 \\
Conversion to surgery $(\%)$ & $2(2.4 \%)$ & - & - \\
Intraprocedural death (\%) & $2(2.4 \%)$ & 0 & .50 \\
\hline $\mathrm{n}$ (\%) listed for categorical variables. $T A V I$, Transapical antegrade aortic valve im- \\
plantation; AVR, aortic valve replacement; $n / a$, not available. &
\end{tabular}

NYHA functional class III $(62.8 \%)$ or IV $(19.5 \%)$ with mean NYHA of $3.1 \pm 0.6$ and $3.2 \pm 0.6$ for TAVI and AVR, respectively. Postoperatively, marked improvement in patients' NYHA class was noted in both cohorts and this effect remained stable to the latest follow-up. At 30 days, $73.2 \%(n=120)$ of patients had improved by 1 or more NYHA classes. At 180 days postoperatively, mean NYHA class was $2.2 \pm 0.8$ and $2.3 \pm 1.0$ for TAVI and AVR, respectively.

\section{DISCUSSION}

TAVI has become the treatment of choice at many centers for patients with severe aortic stenosis and no surgical options owing to exceedingly high operative risk. As recently shown in the multicenter prospective randomized Placement of AoRTic TraNscathetER Valve (PARTNER) trial, TAVI is effective in reducing all-cause mortality in patients with inoperable conditions compared with best medical therapy. ${ }^{13}$ Furthermore, TAVI has been advocated to decrease operative morbidity and mortality in patients at high surgical risk inasmuch as it eliminates the need for median sternotomy, cardiopulmonary bypass, and aortic crossclamping with their respective inherent risks. However, to date little evidence exists on the effectiveness of TAVI compared with surgical AVR as the reference treatment for aortic stenosis. In 2009, Zierer and coworkers ${ }^{14}$ presented a study on their initial experience in 21 patients undergoing transapical TAVI and compared outcomes to a matched group of 30 patients after minimally invasive surgical AVR via a partial upper sternotomy. They found that TAVI resulted in faster postoperative recovery, for example, shorter postoperative ventilation times and shorter duration
TABLE 3. Acute postoperative results and complications

\begin{tabular}{|c|c|c|c|}
\hline & $\begin{array}{c}\text { TAVI } \\
(\mathbf{n}=82)\end{array}$ & $\begin{array}{c}\text { AVR } \\
(\mathrm{n}=\mathbf{8 2})\end{array}$ & $\begin{array}{c}P \\
\text { value }\end{array}$ \\
\hline Ventilation time (min) & $5.1 \pm 20.6$ & $19.9 \pm 14.7$ & $<.001$ \\
\hline Patients extubated in OR & $59(72.0 \%)$ & 0 & $<.001$ \\
\hline Duration of ICU stay (d) & $2.5 \pm 2.2$ & $3.8 \pm 3.3$ & .008 \\
\hline Duration of hospital stay (d) & $13.5 \pm 13.1$ & $10.6 \pm 7.7$ & .11 \\
\hline $\begin{array}{l}\text { Mean gradient at discharge } \\
\quad(\mathrm{mm} \mathrm{Hg})\end{array}$ & $11.3 \pm 5.6$ & $11.8 \pm 5.3$ & .62 \\
\hline $19 \mathrm{~mm}$ & $\mathrm{n} / \mathrm{a}$ & $8.8 \pm 5.1$ & - \\
\hline $21 \mathrm{~mm}$ & $\mathrm{n} / \mathrm{a}$ & $12.9 \pm 4.7$ & - \\
\hline $23 \mathrm{~mm}$ & $11.8 \pm 6.2$ & $12.7 \pm 5.9$ & - \\
\hline $25 \mathrm{~mm}$ & $\mathrm{n} / \mathrm{a}$ & $7.6 \pm 3.4$ & - \\
\hline $26 \mathrm{~mm}$ & $10.5 \pm 4.3$ & $\mathrm{n} / \mathrm{a}$ & - \\
\hline $27 \mathrm{~mm}$ & $\mathrm{n} / \mathrm{a}$ & $10.8 \pm 6.0$ & - \\
\hline $29 \mathrm{~mm}$ & $5.3 \pm 1.2$ & $\mathrm{n} / \mathrm{a}$ & - \\
\hline $\begin{array}{l}\text { Peak gradient at discharge } \\
\quad(\mathrm{mm} \mathrm{Hg})\end{array}$ & $21.5 \pm 10.0$ & $22.9 \pm 10.1$ & .41 \\
\hline $\begin{array}{l}\text { Paravalvular aortic } \\
\text { regurgitation (grade) }\end{array}$ & $0.8 \pm 0.7$ & 0 & $<.001$ \\
\hline $\begin{array}{l}\text { Total amount of bleeding } \\
(\mathrm{mL})\end{array}$ & $521.1 \pm 844.1$ & $888.6 \pm 1477.3$ & .07 \\
\hline Transfusion (units PRBC) & $0.1 \pm 0.6$ & $1.8 \pm 1.7$ & $<.001$ \\
\hline Patients receiving transfusion & $6(7.3 \%)$ & $53(64.6 \%)$ & $<.001$ \\
\hline Impaired wound healing & $5(6.1 \%)$ & $3(3.7 \%)$ & .72 \\
\hline Pacemaker implantation (\%) & $3(3.7 \%)$ & $2(2.4 \%)$ & 1.00 \\
\hline Stroke to 30 days & $2(2.4 \%)$ & $2(2.4 \%)$ & 1.00 \\
\hline Thirty-day mortality (\%) & $6(7.3 \%)$ & $7(8.6 \%)$ & 1.00 \\
\hline
\end{tabular}

$\mathrm{n}(\%)$ listed for categorical variables. TAVI, Transapical antegrade aortic valve implantation; $A V R$, aortic valve replacement; $O R$, operating room; $I C U$, intensive care unit; $P R B C$, packed red blood cells; $n / a$, not available.

of intensive care unit and overall hospital stay. Regarding acute and 1-year mortality, no statistically significant differences were observed, although there was a trend toward more favorable outcome in the surgical group. However, since the initial TAVI experience was compared with an established concept of minimally invasive AVR, this

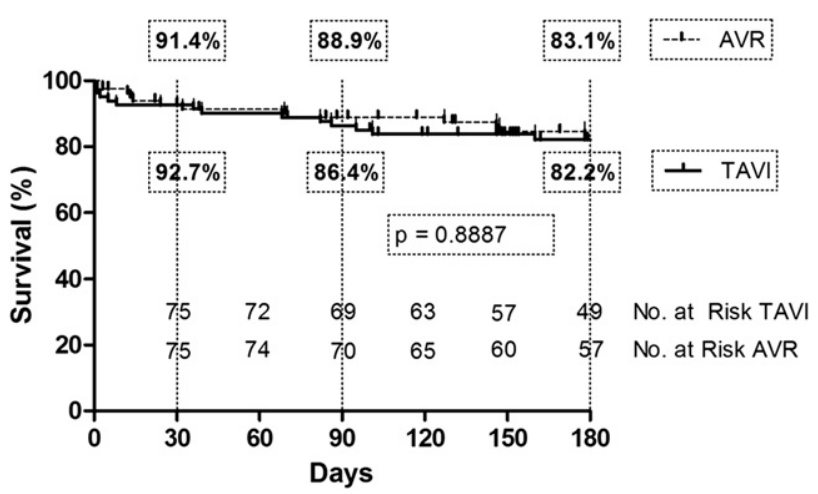

FIGURE 1. Kaplan-Meier survival curves for patients receiving TAVI compared to a surgical control group after AVR. During a follow-up of 180 days, no statistically significant differences were noted. TAVI, Transapical antegrade aortic valve implantation; $A V R$, aortic valve replacement. 


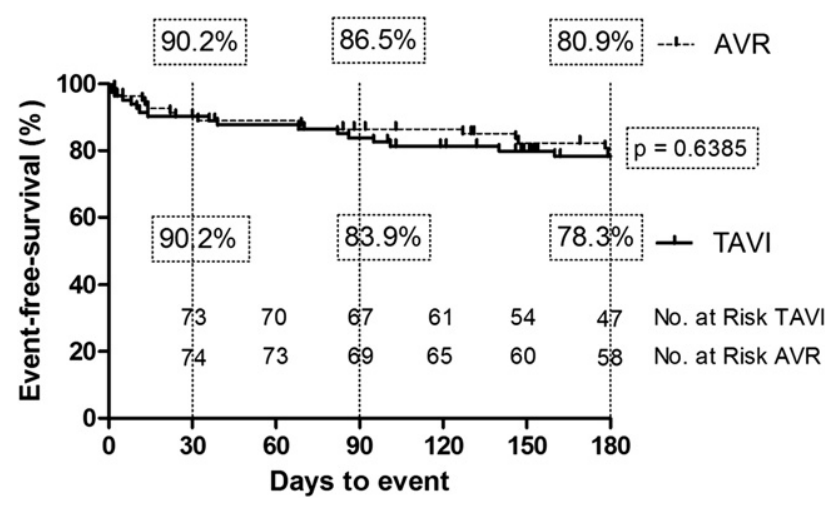

FIGURE 2. Kaplan-Meier analysis for survival free of major adverse cardiac and cerebrovascular events (ie, death, stroke, acute myocardial infarction, reoperation). Event rates were similar between the 2 cohorts. $T A V I$, Transapical antegrade aortic valve implantation; $A V R$, aortic valve replacement.

observation may at least in part result from the learning curve associated with any new surgical procedure.

In another study, 100 consecutive transapical TAVI procedures were compared with 100 propensity-score matched cases of surgical AVR. Patients undergoing TAVI had a significantly higher likelihood to be managed without any intensive care unit stay postoperatively and benefited from an insignificantly lower stroke rate than surgical candidates. Mortality rates were not different between the 2 approaches. ${ }^{15}$

In the present study, we present the results from a singlecenter, real world experience with outcomes after 82 consecutive transfemoral or transapical TAVI procedures using the Edwards Sapien heart valve. The results from both the transcatheter and the surgical control group seem acceptable, particularly when considering the high surgical risk of the study population. Similar to the 2 previous studies, ${ }^{14,15}$ we found significant advantages for patients undergoing TAVI regarding ventilation time and duration of stay in the intensive care unit, suggesting faster postoperative recovery when compared with patients after AVR. However, this did not translate into shorter overall duration of hospital stay in the TAVI cohort, mostly owing to the fact that TAVI patients were kept under continuous electrocardiographic surveillance for an extended period after the procedure for detection of late occurrence of conduction disorders.

Furthermore, lower transfusion requirements were noted in the TAVI cohort. There was a significantly higher mean grade of postoperative aortic regurgitation in the TAVI cohort. Fifty percent of patients had some degree of paravalvular leakage, which was trivial or mild in all but 1 patient. The latter, however, had an uneventful clinical course, and no signs of hemolysis were observed in any patient. Neither impaired left ventricular function nor grade of paravalvular leakage had a negative impact on patient outcome in our series.

Even though mean valve size was significantly larger in the TAVI cohort, postprocedural peak and mean transvalvular gradients were similar compared with the AVR cohort. Possibly, this is at least in part due to incomplete expansion of TAVI prostheses, especially in patients with heavily calcified valve cusps. Correspondingly, severe PPM was present in $10(12.2 \%)$ TAVI patients but only in $1(1.2 \%)$ AVR patient. However, in this population of elderly, comorbid patients, PPM did not seem to influence survival during a follow-up of 180 days.

In our experience, operative mortality was lower than predicted by logistic EuroSCORE, even though the EuroSCORE is known to overestimate operative risk especially in these high-risk patients. ${ }^{16}$ Furthermore, adequateness of standard surgical risk stratification tools for the evaluation of risks inherent in TAVI procedures remains controversial. ${ }^{17}$ Regarding mortality, no significant differences were found between the 2 respective cohorts in our experience. Overall 30- and 180-day mortality rates correspond to those reported from other European single-center experiences or national registries. ${ }^{15,18-21}$

To date, results from only 1 prospective randomized trial exist comparing outcomes after TAVI and surgical AVR in high-risk patients. Data of the PARTNER Trial Cohort A were recently published. ${ }^{22}$ Patients were randomized to receive either transfemoral or transapical TAVI $(n=348)$ or surgical AVR $(n=351)$. The primary end point of the study was all-cause mortality at 1 year; secondary end points included safety and clinical effectiveness issues. Overall 30day mortality was $3.4 \%$ in the TAVI cohort, which is the lowest reported in any TAVI series to date, compared with $6.5 \%$ in the surgical cohort $(P=.07)$. Exclusion criteria as defined in the study protocol, such as severely reduced left ventricular function (LVEF $<20 \%$ ) or severe renal dysfunction (serum creatinine $>3.0 \mathrm{mg} / \mathrm{dL}$ or dialysis dependent), may have contributed to this difference when compared with the European experience.

After 1 year, mortality was $24.2 \%$ in the TAVI cohort versus $26.8 \%$ in the surgical cohort, meeting the noninferiority hypothesis $(P=.001)$. The study investigators conclude that TAVI is an acceptable alternative to surgical AVR for selected high-risk patients.

\section{CONCLUSIONS}

In conclusion, our results and the results of other observational trials, as well as the randomized PARTNER trial, suggest the decision for TAVI or AVR for treatment of aortic stenosis in high-risk patients has to be based on clinical judgment and on the individual patient's characteristics and risk factors. At present, TAVI and AVR seem to be complementary approaches for treatment of high-risk patients with severe aortic stenosis and permit a patient-orientated, 
tailor-made treatment strategy. Decision for one or the other treatment option should be made within a heart center by an interdisciplinary dedicated heart valve team including cardiologists, cardiac surgeons, cardiac anesthetists, and intensive care physicians and should be independent from any financial or budget-related bias. It seems likely that with technical refinement of existing devices and mounting clinical experience of implanting physicians, further improvement of clinical outcome after TAVI can be anticipated. The question whether this development will justify extension of the technique to patients with a lower risk profile cannot be answered at present and warrants the conductance of further randomized trials.

\section{Limitations}

The present study did not randomize patients to receive either TAVI or AVR. Therefore, unknown and potentially confounding variables may have had an impact on outcomes. However, risk adjustment yielded 2 patient cohorts that were similar regarding many baseline demographics and risk factors. The retrospective nature and limited patient number in this study are further potential limitations.

\section{References}

1. Gummert JF, Funkat A, Beckmann A, Schiller W, Hekmat K, Ernst M, et al. Cardiac surgery in Germany during 2006: a report on behalf of the German Society for Thoracic and Cardiovascular Surgery. Thorac Cardiovasc Surg. 2007;1:343-50.

2. Bose AK, Aitchison JD, Dark JH. Aortic valve replacement in octogenarians. $J$ Cardiothorac Surg. 2007;2:33.

3. Melby SJ, Zierer A, Kaiser SP, Guthrie TJ, Keune JD, Schuessler RB, et al. Aortic valve replacement in octogenarians: risk factors for early and late mortality. Ann Thorac Surg. 2007;83:1651-6.

4. Sundt T, Bailey MS, Moon MR, Mendeloff EN, Huddleston CB, Pasque MK, et al. Quality of life after aortic valve replacement at the age of $>80$ years. Circulation. 2000;102(19 Suppl. 3):III70-4.

5. Thourani VH, Ailawadi G, Szeto WY, Dewey TM, Guyton RA, Mack MJ, et al. Outcomes of surgical aortic valve replacement in high-risk patients: a multiinstitutional study. Ann Thorac Surg. 2011;91:49-56.

6. Brown ML, Pellikka PA, Schaff HV, Scott CG, Mullany CJ, Sundt TM, et al. The benefits of early valve replacement in asymptomatic patients with severe aortic stenosis. J Thorac Cardiovasc Surg. 2008;135:308-15.

7. Iung B, Cachier A, Baron G, Messika-Zeitoun D, Delahaye F, Tornos P. Decision-making in elderly patients with severe aortic stenosis: why are so many denied surgery? Eur Heart J. 2005;26:2714-20.

8. Webb JG, Pasupati S, Humphries K, Thompson C, Altwegg L, Moss R, et al. Percutaneous transarterial aortic valve replacement in selected high-risk patients with aortic stenosis. Circulation. 2007;116:755-63.

9. Walther T, Simon P, Dewey T, Wimmer-Greinecker G, Falk V, Kasimir MT, et al. Transapical minimally invasive aortic valve implantation: multicenter experience. Circulation. 2007;116(11 Suppl):I240-5.

10. Conradi L, Seiffert M, Franzen O, Baldus S, Schirmer J, Meinertz T, et al. First experience with transcatheter aortic valve implantation and concomitant percutaneous coronary intervention. Clin Res Cardiol. 2011;100:311-6.

11. Seiffert M, Franzen O, Conradi L, Baldus S, Schirmer J, Meinertz T, et al. Series of transcatheter valve-in-valve implantations in high-risk patients with degenerated bioprostheses in aortic and mitral position. Cath Cardiovasc Interv. 2010;76: 608-15.

12. Conradi L, Treede H, Franzen O, Seiffert M, Baldus S, Schirmer J, et al. Transcatheter aortic and mitral valve interventions: update 2010. Interv Cardiol. 2010; 2:513-23.

13. Leon MB, Smith CR, Mack M, Miller DC, Moses JW, Svensson LG, et al. Transcatheter aortic-valve implantation for aortic stenosis in patients who cannot undergo surgery. N Engl J Med. 2010;363:1597-607.
14. Zierer A, Wimmer-Greinecker G, Martens S, Moritz A, Doss M. Is transapical aortic valve implantation really less invasive than minimally invasive aortic valve replacement? J Thorac Cardiovasc Surg. 2009;138:1067-72.

15. Walther T, Schuler G, Borger MA, Kempfert J, Seeburger J, Rückert Y, et al Transapical aortic valve implantation in 100 consecutive patients: comparison to propensity-matched conventional aortic valve replacement. Eur Heart J. 2010;31:1398-403

16. Rosenhek R, Iung B, Tornos P, Antunes MJ, Prendergast BD, Otto CM, et al. ESC working group on valvular heart disease position paper: assessing the risk of interventions in patients with valvular heart disease. Eur Heart J. 2011 Mar 15 [Epub ahead of print].

17. Mack MJ. Risk scores for predicting outcomes in valvular heart disease. How useful? Curr Cardiol Rep. 2011;13:107-12.

18. Elhmidi Y, Bleiziffer S, Piazza N, Hutter A, Opitz A, Hettich I, et al. Incidence and predictors of acute kidney injury in patients undergoing transcatheter aortic valve implantation. Am Heart J. 2011;161:735-9.

19. Bosmans JM, Kefer J, De Bruyne B, Herijgers P, Dubois C, Legrand V, et al. Procedural, 30-day and one year outcome following CoreValve or Edwards transcatheter aortic valve implantation: results of the Belgian national registry. Interact Cardiovasc Thorac Surg. 2011 Feb 24 [Epub ahead of print].

20. Figulla L, Neumann A, Figulla HR, Kahlert P, Erbel R, Neumann T. Transcatheter aortic valve implantation: evidence on safety and efficacy compared with medical therapy. A systematic review of current literature. Clin Res Cardiol. 2011;100:265-76.

21. Seiffert M, Treede H, Franzen O, Conradi L, Schimer J, Baldus S, et al. Mortality after transapical aortic valve implantation is not related to the procedure but to the preoperative risk. Thorac Cardiovasc Surg. 2010;58(Suppl.1):S116.

22. Smith CR, Leon MB, Mack MJ, Miller DC, Moses JW, Svensson LG, et al. Transcatheter versus surgical aortic-valve replacement in high-risk patients. $N$ Engl $J$ Med. 2011;364:2187-98.

\section{Discussion}

Dr Vinod H. Thourani (Atlanta, $G a$ ). My disclosure is I am an investigator and on the steering committee for the Edwards PARTNER trial. I appreciate the opportunity to discuss this important and timely paper by Dr Conradi and his colleagues from Hamburg, Germany. I also want to thank the authors for providing me a copy of their manuscript and the slides in advance.

The authors are to be congratulated for excellent outcomes in a "real world" scenario outside the confines of a research trial comparing 82 patients undergoing TAVI within the past year with 82 propensity-matched surgical AVR patients over an 8- to 9 -year period. In this group, the authors performed 62 transapical and 22 transfemoral valve implantations, information that was not shown in the slides but is in the manuscript that was given to me. They noted a respectable overall mortality of $7.3 \%$ in the transcatheter group and $8.6 \%$ in the surgical AVR group. The stroke rate was 2 patients, or $2.4 \%$, in each group, and transfusion of less than 1 unit of blood in the transcatheter group, which is excellent. Overall, they have concluded similar results in short-term outcomes of patients undergoing isolated AVR with an average Society of Thoracic Surgeons predicted risk of mortality of approximately $9 \%$. So, again, congratulations are due for those outcomes.

I have a couple of questions for the authors. First, you note the paravalvular leak rate comparing the transcatheter valve and the surgical valve group. Was there an associated morbidity and mortality in those patients, especially in those that have a diminished ejection fraction? Can you comment on the rate of paravalvular leakage between the 2 groups?

Dr Conradi. Thank you, Dr Thourani, for those questions. When looking at regurgitation rates, we found that about $50 \%$ 
of our TAVI patients in this population, 41 patients, had some degree of paravalvular leakage. However, in the vast majority of these patients, in 40 of those, this was trivial to mild and did not have any clinical consequence. In only 1 patient was there a degree of paravalvular regurgitation that was graded as moderate. In the surgical group, we did not see any relevant paravalvular leakage. The regurgitation that we saw here was central, as is known to occur with pericardial prostheses.

We did not see any influence on the outcome of these 82 patients.

Dr Thourani. We have had problems with patients who have low ejection fractions, $20 \%$ to $25 \%$. Even when we leave them with mild aortic regurgitation, they continue to be admitted for heart failure. It does not seem as though you have seen what we have seen here in the United States at times.

Dr Conradi. In this cohort, we have not, but I can say that in patients with pronounced cardiomyopathy, we tend to use the CoreValve device (Medtronic, Inc, Minneapolis, Minn) rather than the Edwards device because it does not need rapid ventricular pacing for implantation. We believe that may be advantageous for the patient, to some extent, and maybe this is the bias that we have. As a consequence, we do not see the effects that you are alluding to in this particular cohort of patients receiving Edwards Sapien valves.

Dr Thourani. It sounds like an interesting paper for next year's Association meeting.

Can you note the median valve size used in the surgical AVR patients as compared with the TAVR patients? Have you seen any outcome differences with patient-prosthesis mismatch, which we have already heard about in the valve-in-valve from your site?

Dr Conradi. Thank you for the question. The mean size was $24 \mathrm{~mm}$ in the TAVI patients and $22 \mathrm{~mm}$ in the surgical patients. There seems to be a difference, and it is indeed statistically significant. However, these are 2 different valve types. If you consider the technique of implantation, for example, a 23-mm TAVI is not a $23-\mathrm{mm}$ surgical valve. Furthermore, because you also have to consider the extent of calcification present within the native valve and annulus, extension of the TAVI device may be different from patient to patient. Therefore, it is hard to draw conclusions just by the manufacturer-given valve sizes that were implanted.

Dr Thourani. In the manuscript, you report that a lot of your patients have size 19 valves. Have you seen any major problems from the surgical patients having only a $19-\mathrm{mm}$ valve inserted? Comparably, in the transcatheter patients the smallest valve was $23 \mathrm{~mm}$. Is there any outcomes difference between the patients receiving $19-\mathrm{mm}$ valves surgically versus the larger valve effective orifice areas for the transcatheter patients?

Dr Conradi. From the 82 patients in the surgical cohort, 7 received 19-mm valves. I do know that, maybe not from these particular 7 patients but in general from our experience, we did see the same kind of problems that you were alluding to in our experience, also. Whenever we can, we try to avoid these small prostheses, especially now with valve-in-valve technology being an option for the future in these patients.

Dr Thourani. Although not discussed in your presentation, you have not really broken out transapical or transfemoral techniques, so you are putting the whole transcatheter group into one. Are there any major differences between the transapical and transfemoral approaches in the surgical AVR group?

Dr Conradi. Yes, we looked into that. The relation, as you pointed out in the beginning, was 60 transapicals versus 22 transfemorals. We did not see a major difference in this particular subset of patients regarding outcome, even though the baseline characteristics may have differed between the 2 . We were surprised by that finding at the beginning, but these are the facts and how we see them.

Dr Thourani. I guess that leads to the question of what should be chosen then. Somebody asked that earlier in the previous presentation. When a patient comes in, looking at your data and the data presented from other people at this meeting, do you use a transapical or a transfemoral approach or do you do a surgical AVR, and how do you make that decision? I presume you are still putting in surgical valves in patients. How do you make that differentiation from Hamburg? What can we learn from you?

Dr Conradi. We have a transfemoral-first policy at our site, and we have the same contraindications for that kind of approach as many other investigators have. Severe peripheral artery disease may preclude transfemoral access, as may small caliber vessels, even though the XT device has somewhat diminished that hurdle. Furthermore, we also look very closely at the aorta; tortuosity or atherosclerosis or even aneurysm formation of the abdominal aorta may be a problem, as is severe calcification of the aortic arch. All in all, we have a pretty liberal stance on using transapical access.

Dr Marc R. Moon (St Louis, Mo). You said you have a transfemoral-first approach. Is age then irrelevant at your institution?

Dr Conradi. Do you mean for the decision?

Dr Moon. If a 40-year-old patient comes in, does he or she get a transfemoral-first approach?

Dr Conradi. No. I mean transfemoral first within the TAVI candidates. After deciding for TAVI, we have a transfemoral-first policy.

Dr Moon. Since all your patients were at the same institution, were you able to perform any cost data comparison?

Dr Conradi. We have a special situation in Germany. Reimbursement for TAVI is very high. It is possible that in other institutions this may be a reason for a TAVI or against surgery. I do not know. With our approach, it certainly is not. We have the heart team approach, and we look at each and every one of these patients with our cardiology colleagues. For example, we would never use age alone as a criterion for a TAVI or against surgery but rather relate that to the general status of the patient and comorbidities and so on.

Dr Lucian Lozonschi (Madison, Wis). First, was this study done with only the Edwards Sapien valve or were there any CoreValves also? It was not clear from your slides. Second, the mortality in both groups was high and actually higher than that reported in the PARTNER trial in the surgical group. I have a question also, regarding the paravalvular leak. You mentioned there was some aortic regurgitation. We all know that aortic regurgitation is hard to assess after TAVI, because there are multiple jets; there is a central jet as well as paravalvular jets. And the data in the PARTNER trial were rigorously checked by an independent core laboratory. In the real-life situation, it is going to be hard to report how pleased we are with "some" aortic regurgitation, and I think there may be more patients with more than mild regurgitation than in your 
group. I was struck by the low incidence of paravalvular leak, especially in the TAVI group. Can you comment, please?

Dr Conradi. Thank you for these important questions. The first question was whether this was an Edwards-only cohort. As stated on the methods slide, it was. These were 82 consecutive Edwards patients. Within the same time frame, we did perform CoreValve implantations, but these were not included in the study.

Regarding your comment about the PARTNER trial, I agree that results were more favorable here in that trial. However, if you look at the study design, there were important exclusion criteria for patients in the PARTNER trial, such as severe heart failure or severe renal insufficiency. We did not have any of these exclusion criteria. This was a real world experience. If you compare our series to other series, like the Munich experience, other groups get results similar to ours with this approach.

Regarding paravalvular leakage, you are completely right that assessment of paravalvular leakage is not that easy, and grading is not either. All of these patients were followed in our outpatient clinic by our cardiology colleagues, and we have deep confidence that they assess paravalvular leakages in a correct manner. 